\title{
Clase y estratificación social en Argentina, 1947-2010
}

\author{
Adrián Piva \\ CONICET/Universidad Nacional de Quilmes/Universidad de Buenos Aires \\ adrianpiva@gmail.com
}

\section{Resumen}

Este artículo tiene dos objetivos. Primero, aproximarse al análisis empírico de las tendencias de evolución de las relaciones de clase desde 1947 —enfatizando en la composición de clase de los asalariados - y de los procesos de estratificación social desde 1980 en Argentina. Para ello, se realiza una comparación de la evolución de dimensiones teóricamente significativas entre los períodos 1947-1974 y 1974-2010 a partir de los censos nacionales de población de 1947 a 2010 y de los censos económicos de 1947 a 2004. En segundo lugar, obtener algunas conclusiones del estudio de caso sobre la productividad, complementariedad y oposición de las nociones marxista y sociológica de clase. El análisis marxista de clase muestra una ruptura en las tendencias de evolución entre los períodos 1947-1974 y 1974-2010. En el primero, la dualización de la estructura económica tendió a coincidir con la oposición ciudad/campo, lo que impulsó una dinámica homogeneizadora del trabajo urbano. Entre 1974 y 2010, la dualización de la estructura económica que produjo el proceso de acumulación atravesó la oposición campo/ciudad, creando una creciente heterogeneidad del trabajo urbano. A su vez, se observa desde 1980 una tendencia al crecimiento de los estratos medios, explicada por la expansión de asalariados técnicos y profesionales. El estudio simultáneo de los procesos de constitución de las relaciones sociales como relaciones de clase (perspectiva marxista) y de diferenciación social según oportunidades de vida (perspectiva sociológica) permite aprehender las condiciones estructurales de potenciales procesos de composición/descomposición política de clases.

Palabras clave: clases; estratificación social; marxismo; sociología 
Abstract. Class and social stratification in Argentina, 1947-2010

This article has two objectives. The first is to empirically analyze trends in the evolution of class relations since 1947-emphasizing the class composition of waged workers - and processes of social stratification since 1980 in Argentina. To this end, the evolution of theoretically significant dimensions in the periods 1947-1974 and 1974-2010 is compared using data from the national population censuses from 1947 to 2010 and the economic censuses from 1947 to 2004 . The second aim is to obtain some conclusions from the case study on the productivity, complementarity and opposition of the Marxist and sociological notions of class. The Marxist class analysis shows a break in the trends of evolution in the periods 1947-1974 and 1974-2010. In the first period, the dualization of the economic structure tended to coincide with the urban/rural opposition, which fostered the homogenization of urban work. From 1974 to 2010, however, the dualization of the economic structure caused by the accumulation process placed impediments on the rural/ urban opposition, leading to the growing heterogeneity of urban work. At the same time, a trend towards the growth of the middle strata since 1980 has been observed, which is explained by the expansion of technical and professional waged workers. The simultaneous study of the processes of constitution of social relations as class relations (Marxist perspective) and social differentiation according to life opportunities (sociological perspective) provides insight on the structural conditions of potential processes of political composition/ decomposition of classes.

Key words: class; social stratification; Marxism; sociology

\section{Sumario}

1. Introducción 4. Una propuesta de análisis marxista

2. Algunas aclaraciones conceptuales

3. La periodización del modo de acumulación de capital en la Argentina contemporánea de clase: el caso argentino entre 1947 y 2010

5. Una aproximación al análisis empírico desde la perspectiva sociológica

6. Conclusiones

Referencias bibliográficas

\section{Introducción}

El artículo que presentamos tiene un doble propósito. En primer lugar, realizar un análisis empírico de las tendencias de evolución de las relaciones estructurales de clase desde 1947, con énfasis en la composición de clase de los asalariados, y de los procesos de estratificación social desde 1980 en Argentina. Con ese fin, se lleva a cabo una comparación de las tendencias de evolución de dimensiones teóricamente significativas entre los períodos 1947-1974 y 1974-2010 a partir de los censos nacionales de población de 1947 a 2010 y de los censos económicos de 1947 a 2004. La selección de los períodos, limitada por los años de los que se disponen fuentes censales, obedece a una periodización de los modos de acumulación de capital en Argentina, entendiendo que 
existe una fuerte correlación entre tendencias de la acumulación de capital y tendencias de transformación de las relaciones de clase y de la estructura de estratificación social. En segundo lugar, pretendemos contrastar empíricamente en un estudio de caso la reconceptualización de las nociones marxista y sociológica de clase propuesta en trabajos anteriores (Piva, 2017a) con el objetivo de obtener algunas conclusiones sobre su productividad, complementariedad y oposición. De este modo, buscamos realizar un aporte a la comprensión de las tendencias de transformación de largo plazo de la estructura social argentina y a la elaboración de nuevas propuestas teóricas para el estudio de procesos de diferenciación social en sociedades capitalistas.

Por esa razón, dedicaremos el primer apartado a una exposición resumida de las nociones marxista y sociológica de clase. En el segundo apartado, aportaremos elementos para una periodización del modo de acumulación en Argentina, esencial para justificar los períodos de comparación y para establecer la significación de algunos de los resultados obtenidos. En el tercer apartado, avanzamos en el análisis empírico de las relaciones estructurales de clase desde la conceptualización marxista, y en el cuarto apartado emprendemos un análisis exploratorio de los procesos de estratificación social a partir de un modelo construido para el caso argentino. Por último, en las conclusiones, después de reponer los principales resultados empíricos, consideramos la relevancia y función de los conceptos marxista y sociológico de clase para comprender procesos de composición/descomposición política de clase.

\section{Algunas aclaraciones conceptuales}

El punto de partida del análisis es la distinción entre la noción marxista de clase y la noción sociológica de clase o de estratificación social. ${ }^{1}$

La concepción marxista de las clases tiene un largo desarrollo, aunque los intentos de sistematización son relativamente recientes y se remontan a la obra de Poulantzas desde fines de los años 60 (Poulantzas, 1975; 1985). La obra de Poulantzas originó importantes debates que impulsaron su crítica y reconceptualización, en particular en torno al viejo problema de las clases medias (Carchedi, 1977; Wright, 1983), pero indudablemente el trabajo teórico y empírico de mayor relevancia ha sido el de Erik Olin Wright (1983, 1994, 1997, 2015). Sin embargo, y a pesar de los importantes progresos que han comportado para la perspectiva marxista, todos estos intentos de sistematización han, implícita o explícitamente, asumido supuestos básicos de la sociología de la estratificación social. En particular, la separación entre posiciones e individuos, lo que implica que el principal problema pasa a ser el de la distribución y clasificación de los individuos en la estructura de posiciones según criterios teóricamente significativos. Pero, como ha señalado Richard Gunn (2004), para Marx la clase (al igual que la mercancía o el capital) es ante todo una relación social que no puede ser reducida a un sistema de posiciones. Dicho de otro modo, el prin-

1. Retomamos esta nomenclatura de Gunn y Holloway (Gunn 2004; Holloway 2004). 
cipal problema del enfoque marxista de las clases no es el de la clasificación/ distribución de individuos, sino la comprensión de las relaciones que los constituyen como sujetos. Aquí se presenta de manera resumida una propuesta de conceptualización de clase que será la base del análisis empírico (Piva, 2017a).

La separación del productor directo de los medios de producción es condición de su libertad (necesidad) y de su igualdad (explotación) frente al capitalista. Por lo tanto, la relación de capital resulta objetivamente contradictoria en la medida en que constituye a los pares opuestos igualdad-libertad/ desigualdad-coacción como polos de la misma relación, esto es, para decirlo en los términos de Laclau y Mouffe, en la medida en que constituye simultáneamente la relación de subordinación y la perspectiva normativa desde la que es posible mirarla como relación de opresión (Laclau y Mouffe, 2004). Pero en la contradicción capital/trabajo, tal como se la ha presentado aquí, no está dada todavía la «forma clase». Esta supone el análisis del modo particular de subjetivación que caracteriza a la relación de capital. Ese proceso de subjetivación es estructurado por la forma salario, es decir, por la transformación del precio de la fuerza de trabajo en precio del trabajo. A través de la relación salarial, las personas se enfrentan como personificaciones del capital y del trabajo, es decir, como ejemplares individuales de clase. Se trata, en este nivel de análisis, de una relación social objetiva (independiente de la conciencia, identidad y voluntad de las personas) y antagónica, ya que se funda en aquella contradicción objetiva. La contradicción objetiva interna a la relación asalariada aparece ahora como antítesis externa, como oposición entre polos subjetivos de una relación. La relación salarial abarca los momentos de la circulación y de la producción. No se limita al intercambio, ya que la forma de pago del salario estructura la extracción de excedente en la producción. Pero en la producción la relación de clase asume características específicas, ya que allí domina el carácter despótico de la relación de capital. En la producción, la personificación del capital es tal en la medida que ejerce el poder de mando sobre el trabajo. Nuevamente la clase es una relación entre personificaciones del trabajo y del capital, pero aquí aparecen individuos que se enfrentan simultáneamente como personificaciones del capital frente al trabajo, en tanto llevan a cabo tareas de supervisión y dirección del proceso de trabajo, y como personificaciones del trabajo frente al capital, en la medida que son, al menos parcialmente, asalariados. Por último, los individuos se relacionan como ejemplares de «clase» no solo en el sentido de que se presentan como representantes de los recursos capital y trabajo, es decir, no simplemente porque podamos reunirlos por el tipo de recurso que poseen, sino porque crecientemente sus condiciones sociales de existencia son colectivas. Desde la cooperación simple hasta la gran industria, y a medida que crecen la concentración y la centralización del capital, la existencia de trabajadores y capitalistas es crecientemente una existencia colectiva, como obrero y capitalista colectivo. El concepto de obrero colectivo abarca tanto a trabajadores productivos como a trabajadores improductivos, ya que cada vez más los cambios en las condiciones de venta y uso de la fuerza de trabajo en cualquier esfera del trabajo social afectan las 
condiciones de venta y uso de la fuerza de trabajo en las restantes esferas. El análisis de la composición de clase (Tronti, 2001; Negri, 2001) es entonces el análisis de atributos colectivos de un individuo colectivo y de las relaciones entre sus elementos componentes, en tanto dimensiones de lo que podemos llamar momento 1 de las relaciones de fuerzas sociales entre clases o momento objetivo.

Mientras que la «noción marxista» de clase es la de una relación social objetiva, la "noción sociológica» es nominalista, las "clases sociológicas» son distribuciones y clasificaciones de los individuos según atributos significativos. Su principal objetivo es determinar/predecir chances diferenciales de vida de los individuos a partir de su posición en dicha distribución (situación de clase) (Weber, 2002). Los modelos clásicos de estratificación social se han desarrollado a partir de la sociología funcionalista (Parsons, 1976), pero desde entonces la sociología de la estratificación social ha adquirido autonomía como rama especial de la sociología, y la construcción de modelos se ha complejizado y ha diversificado sus fuentes teóricas (Lockwood, 1962; Goldthorpe y Mcknigth, 2004). Varios de estos modelos, incluyendo las aproximaciones marxistas de Wright (Wright, 1997, 2015), han mostrado capacidades predictivas en investigaciones sobre los países centrales. ¿Cómo interpretar esta capacidad explicativa y qué relevancia tienen estos modelos para un programa de investigación inscripto en la tradición marxista?

El proceso de subsunción del trabajo al capital constituye a los individuos como sujetos. Ello supone que se enfrentan a sus condiciones crecientemente colectivas como a una determinación objetiva, es decir, como límite a su libertad de acción. Pero de lo expuesto ya puede intuirse que la libertad de acción de los individuos y ese límite aparentemente exterior que se les impone no son otra cosa que la contradicción objetiva capital/trabajo que los constituye y atraviesa. Dicho de manera más precisa, la libertad o la coacción para vender la fuerza de trabajo y la capacidad de disponer de la propia fuerza de trabajo o de la de otros en el proceso de producción se «distribuyen» de manera desigual entre el conjunto de los individuos liberados por el progreso del proceso de subsunción del trabajo al capital. Por ejemplo, la libertad de acción es mayor y la sujeción a las "cadenas del capital» es más leve entre aquellos cuyas posibilidades de ser despedidos son menores y/o su «empleabilidad» es mayor o cuanto mayor es la disposición sobre la propia fuerza de trabajo o la de otros. Los estudios de estratificación social son más potentes en sus predicciones respecto de la diferenciación de probabilidades de vida cuanto más significativos sean los atributos seleccionados para identificar el modo desigual en que la libertad/coerción estructura la vida de las personas. El proceso de subsunción del trabajo al capital produce la creciente constitución de las relaciones entre los individuos como relaciones objetivas de clase, al tiempo que crea una diferenciación social fundada en el modo desigual en el que la contradicción capital/ trabajo atraviesa a esos individuos. Un programa de investigación marxista debe ser capaz de aprehender ambos procesos. Volveremos sobre este importante punto en las conclusiones. 
Por último, en lo que refiere a modelos de estratificación social, aquí retomamos la distinción weberiana y neoweberiana entre clase y estatus (Weber, 2002; Chan y Goldthorpe, 2007). La clase sociológica refiere a una relación causal objetiva entre determinados atributos vinculados a la "situación de mercado" y determinadas probabilidades de vida de un grupo humano, relación causal que es independiente de la existencia o no de acción colectiva fundada en esa situación de clase común. El estatus resulta de una orientación de la acción hacia la producción de tal diferenciación y requiere sociabilidad común, determinados modos o estilos de vida compartidos, razón por la cual suele ser más potente a la hora de vincular posiciones sociales y comportamientos individuales. Los estudios centrados en la noción de estrategia, ya sea aquellos basados en la teoría de las diferentes clases de capitales de Bourdieu (Bourdieu, 1988; 1989; Savage et al., 2005) o los estudios neoweberianos de Parkin centrados en la noción de estrategias de cierre social (Parkin, 2001), funden ambos procesos de diferenciación. Dado nuestro interés en la determinación desigual de la vida de los individuos por la contradicción objetiva capital/trabajo, dejamos provisoriamente de lado la diferenciación según estatus.

\section{La periodización del modo de acumulación de capital en la Argentina contemporánea}

El estudio de las características y la periodización del modo de acumulación de capital en Argentina ha sido motivo de debates que se han concentrado, sobre todo, en el período posterior a 1976, existiendo un relativo consenso en torno al período de industrialización por sustitución de importaciones (ISI). En los límites de este artículo no podríamos desarrollar esas discusiones. Lo que pretendemos es justificar el recorte temporal elegido y dar un marco que permita establecer la significación de algunos de los resultados obtenidos. La reconocida relación entre la dinámica de la acumulación de capital y las tendencias de la estructura de clases en Argentina (Iñigo Carrera y Podestá, 1985; Torrado, 1994; Salvia y Quartulli, 2011; Dalle, 2016) torna indispensable una presentación de la periodización del modo de acumulación que este trabajo supone. ${ }^{2}$

Es un tópico de la literatura sobre Argentina que la industrialización mediante sustitución de importaciones tendió a producir una estructura dual a cuya especificidad correspondió una dinámica particular. ${ }^{3}$ Diamand (1972) introdujo el concepto de "estructura productiva desequilibrada» (EPD). Una EPD está compuesta por dos sectores: un sector primario orientado a la exportación que trabaja con productividades cercanas a las internacionales, y un sector industrial orientado al mercado interno y dependiente de la importación de bienes de capital que trabaja con productividades considerablemente inferio-

2. Para un mayor desarrollo véase (Piva, 2017b).

3. Dicha literatura fue influida por la tradición cepalina y su concepto de heterogeneidad estructural (Prebisch, 1949; Pinto, 1970), que aquí no discutimos por razones de espacio. 
res (Diamand, 1972). Al mismo tiempo, Braun y Joy desarrollaban su clásico modelo basado en dos sectores: primario exportador e industrial importador orientado al mercado interno (Braun y Joy, 1981). Ambos modelos fueron la base de la explicación de la dinámica de «stop and go» propia de la economía argentina desde los años 40. Durante la fase de crecimiento, el aumento de la demanda importadora de insumos intermedios y bienes de capital del sector industrial se conjugaba con la reducción de saldos exportables debida al crecimiento de los salarios, ya que los bienes exportables eran bienes de consumo obrero. En un contexto de tendencia a pobres aumentos o cuasi estancamiento de la producción agropecuaria, la dinámica de crecimiento generaba déficit comercial y finalmente una crisis de balanza de pagos. Llegado este punto, se sucedían la devaluación de la moneda, la recesión con fuerte retracción industrial, la caída del salario real y el aumento del desempleo, que, en conjunto con una recuperación de las exportaciones, recomponían las condiciones para un nuevo período de crecimiento.

Sin embargo, a fines de los años 60, en el preciso momento en el que se modelizaban las condiciones del ciclo stop-go, ocurrían cambios que alteraban el ciclo tradicional. En la etapa 1964-1975 los ciclos se moderan y la dinámica se complejiza. El fuerte ingreso de inversión extranjera directa (IED) y el aumento del recurso al endeudamiento externo mejoraron la cuenta capital, mientras que una incipiente reorientación exportadora del gran capital industrial y, fundamentalmente, la mejora en los términos de intercambio aliviaron la balanza comercial (Basualdo, 2006). A ello se sumó la contención salarial, que redujo la presión sobre ganancias y saldos exportables (Basualdo, 2006). La moderación del ciclo dio lugar a un crecimiento continuo con desaceleraciones de ritmo pero que, en lugar de a las recesiones cortas, condujo a una gran crisis en 1975. Tanto la moderación del ciclo como el estallido de la crisis de 1975 responden parcialmente a condiciones mundiales generadas por el agotamiento y la crisis del capitalismo central de posguerra. Por lo tanto, si la crisis de 1975 no fue una crisis más del ciclo stop-go y significó la crisis de la ISI, es porque condensó la acumulación de desequilibrios y contradicciones de la acumulación local y la crisis del orden capitalista de posguerra. Es decir, fue el capítulo local de un proceso de crisis y reestructuración a escala mundial que redefiniría las relaciones Estado-acumulación y mercado nacional-mercado mundial. Por esa razón, el golpe militar de 1976 dio inicio a un largo proceso de ofensiva capitalista y de intentos de reestructuración que le darían el tono de una fase transicional, atravesada por avances profundos de ofensiva y reestructuración, el período 1976-1981, y períodos de resistencia que limitaron o directamente bloquearon su avance, desde el fin de la dictadura hasta la hiperinflación de 1989.

La hiperinflación fue el terreno en el que se desenvolvió una acelerada y radical transformación de las relaciones de fuerza entre capital y trabajo. Por un lado, se produjo una fragmentación y desorganización de la acción colectiva de la clase obrera y una unificación del conjunto de las fracciones de la gran burguesía en torno al programa neoliberal, por otro lado, sobre esa base, se 
articuló un amplio consenso en torno a dicho programa que fue el fundamento de una hegemonía que duraría hasta 2001 y cuyo eje articulador sería la convertibilidad monetaria (Bonnet, 2008; Piva, 2012). El proceso de reestructuración del capital y del Estado dio lugar a un modo de acumulación centrado en la exportación de productos industriales de bajo valor agregado, agroindustriales y agropecuarios (commodities). A su vez, el ritmo de acumulación dependió fuertemente de la IED y de los flujos internacionales de capital-dinero. En ese marco se desarrolló una creciente interpenetración del capital nacional y extranjero y una tendencia a la internacionalización de la propiedad del capital local. El resultado fue un desarrollo caracterizado por la profundización de la dependencia tecnológica y por la "dualización estructural», particularmente de la industria, entre un sector moderno y competitivo (fundamentalmente exportador) y otro atrasado e impulsado por la competencia a la intensificación y extensión de la jornada laboral. Por lo tanto, la primera característica de la dinámica de acumulación fue la fragilidad externa, originada en las fuertes fluctuaciones de precios que afectan los commodities y en la tendencia al desequilibrio comercial del crecimiento industrial, causada por la dependencia tecnológica. La segunda característica fue la vulnerabilidad financiera, debida a la dependencia de los flujos financieros y de la IED. Por último, a medida que el impacto de la reconversión productiva sobre la productividad alcanzaba sus límites, el conjunto de la acumulación se hizo más dependiente de mecanismos de producción de plus valor absoluto (extensión e intensificación de la jornada laboral) y/o de la directa reducción del salario. ${ }^{4}$

El ciclo expansivo terminaría en el último trimestre de 1998 en el contexto de una sucesión de crisis en la periferia (Sudeste Asiático en 1997, Rusia en 1998, Brasil en 1999 y Turquía en 2001). Sin embargo, el régimen de convertibilidad monetaria solo sería abandonado entre diciembre de 2001 y enero de 2002 en el marco de una profunda crisis política y de la mayor crisis económica de la historia argentina.

El nuevo proceso expansivo 2003-2011 se desenvolvió sobre la base de la reestructuración capitalista de la década previa y muestra continuidades esenciales con el modo de acumulación de capital desarrollado en los noventa. Sin embargo, presenta ciertas especificidades.

La mejora de los términos de intercambio - el ciclo de aumento del precio de los commodities iniciado en 2002-y la devaluación del peso posibilitaron niveles de superávit comercial suficientes para ignorar la restricción de acceso al crédito internacional que siguió al default de 2001. Sin embargo, las tendencias al desequilibrio en el sector externo siguieron actuando y reemergerían a partir de 2011. A pesar de la profundización de la reorientación exportadora, persistieron el carácter deficitario del conjunto de la industria en contraposición al superavitario del agro y la tendencia a un aumento mayor de las cantidades importadas respecto de las exportadas durante las fases expansivas.

4. Otros autores caracterizaron el modo de acumulación de capital en los años 90 como una fase de expansión fundada en las finanzas (véase Basualdo, 2006; Schvarzer, 2000). 
Una segunda especificidad fue el proceso de sustitución de importaciones industriales, que, no obstante, no revirtió la pérdida de peso de la industria en la estructura económica (Cantamutto y Constantino, 2016), y que, a diferencia de la sustitución de importaciones de la segunda posguerra, se articuló/ subordinó a la estrategia exportadora del gran capital industrial. Su desarrollo sobre la base de costos salariales relativamente bajos —al menos en los primeros años- $y$, lo que es particularmente claro en la industria textil, del uso de capacidad instalada y empleo precario profundizó la estructura dual de la industria.

Una tercera especificidad fue el carácter predominantemente capital extensivo de la acumulación que explica la rápida caída del desempleo, fundamentalmente entre 2003 y 2007.

En ese contexto, la recuperación del salario real y una política estatal más activa tendieron a aumentar el peso de la demanda interna como motor de la expansión económica — cuarta especificidad del período-, lo que no tardaría en producir tensiones con una acumulación de capital dinamizada por su sector exportador.

El hecho de que estas especificidades se desenvolvieran sobre el trasfondo y los límites de las transformaciones ocurridas en los años 90 habilita el tratamiento de la posconvertibilidad como un subperíodo del período abierto en 1989.

\section{Una propuesta de análisis marxista de clase: el caso argentino entre 1947 y $2010^{5}$}

Cuando intentamos una primera aproximación cuantitativa a la clase concebida como relación social y buscamos identificar a aquellos individuos que se enfrentan como personificaciones del trabajo frente al capital y/o como personificaciones del capital frente al trabajo, encontramos una primera medición, todavía tosca, en su distribución según categoría ocupacional.

En el cuadro 1 podemos ver cómo evoluciona dicha distribución en los censos nacionales de población desde 1947 hasta 2010. Como primera observación se puede señalar que desde 1980 cambian las tendencias de evolución. Entre 1947 y 1970, aumentan de manera continua el número y el porcentaje de «asalariados» $\mathrm{y}$ "cuentapropistas» $\mathrm{y}$ caen absoluta y relativamente los "patrones», mientras que desde 1980 las tendencias son más complejas. Analizaremos ambos períodos por separado y discutiremos los problemas que plantean a nuestro objetivo los límites de comparabilidad de las fuentes censales.

Respecto del período 1947-1970, los mayores problemas de comparabilidad los presenta el censo de 1970, ya que incluye en la definición de la PEA a todos los ocupados y desocupados de 10 años de edad o más, a diferencia

5. La comparabilidad de los censos de población y de los censos económicos se ve limitada por cambios metodológicos. Dado que una discusión pormenorizada de estas diferencias está fuera de las posibilidades de un artículo como este, haremos referencia a estos sesgos cada vez que puedan limitar el análisis. 
Cuadro 1. Distribución de la PEA según categoría ocupacional.

\begin{tabular}{|c|c|c|c|c|c|c|c|c|}
\hline \multirow[b]{2}{*}{ Categoría ocupacional } & \multicolumn{2}{|l|}{1947} & \multicolumn{2}{|c|}{1960} & \multicolumn{2}{|c|}{1970} & \multicolumn{2}{|c|}{1980} \\
\hline & Frecuencia & $\%$ & Frecuencia & $\%$ & Frecuencia & $\%$ & Frecuencia & $\%$ \\
\hline Patrón o empresario & 1.013 .637 & $16,2 \%$ & 920.991 & $12,2 \%$ & 514.600 & $5,7 \%$ & 575.507 & $5,8 \%$ \\
\hline Cuenta propia & 419.058 & $6,7 \%$ & 901.121 & $12,0 \%$ & 1462.300 & $16,2 \%$ & 1.939 .884 & $19,4 \%$ \\
\hline Ayuda familiar & 181.665 & $2,9 \%$ & 5.267 .105 & $2,8 \%$ & 6.380 .500 & $3,2 \%$ & 326.472 & $3,3 \%$ \\
\hline Asalariado & 4.641 .121 & $74,0 \%$ & 214.166 & $70,0 \%$ & 285.850 & $70,8 \%$ & 7.147.327 & $71,6 \%$ \\
\hline Desconocida & 11.832 & $0,2 \%$ & 221.086 & $2,9 \%$ & 368.200 & $4.1 \%$ & 0 & 0 \\
\hline \multirow[t]{2}{*}{ Total } & 6.267 .313 & $100 \%$ & 7.524 .469 & $100,0 \%$ & 9.011 .450 & $100,0 \%$ & 9.989 .190 & $100,0 \%$ \\
\hline & \multicolumn{2}{|c|}{1991} & \multicolumn{2}{|c|}{2001} & \multicolumn{2}{|c|}{2010} & & \\
\hline Categoría ocupacional & Frecuencia & $\%$ & Frecuencia & $\%$ & Frecuencia & $\%$ & & \\
\hline Patrón o empresario & 872.919 & $7,1 \%$ & 680.754 & $6,2 \%$ & 1.190 .944 & $6,6 \%$ & & \\
\hline Cuenta propia & 2.825.191 & $22,8 \%$ & 2.210 .473 & $20,3 \%$ & 3.346 .107 & $18,5 \%$ & & \\
\hline Ayuda familiar & 666.164 & $5,4 \%$ & 367.331 & $3,4 \%$ & 561.078 & $3,1 \%$ & & \\
\hline Asalariado & 7.980 .327 & $64,5 \%$ & 7.654 .629 & $70,1 \%$ & 12.947 .286 & $71,7 \%$ & & \\
\hline Desconocida & 23.727 & $0,2 \%$ & 0 & 0 & 0 & 0 & & \\
\hline Total & 12.368 .328 & $100,0 \%$ & 10.913 .187 & $100,0 \%$ & 18.045 .415 & $100,0 \%$ & & \\
\hline
\end{tabular}

Fuente: censos nacionales de población de 1947, 1960, 1970, INDEC, Argentina.

de los censos anteriores, que consideraban solo a personas de 14 o más años. Dado que no existen cuadros publicados que crucen "categoría ocupacional» y escala de edad en 1970, recurrimos a la evolución de la «tasa de actividad» con el fin de estimar los sesgos posibles implicados en este cambio de medición de la PEA. La "tasa de actividad" medida de acuerdo a la definición de la PEA de cada censo se reduce entre 1960 y 1970 del 52,9\% al 48,9\%, (cuadro 3). Pero cuando solo consideramos los individuos de 15 o más años, la tasa de actividad de 1970 se eleva al 53,3\%, mientras que la tasa de actividad de 1960 se mueve levemente al 53,5\%. Es decir, prácticamente se suprime la caída entre esos años. Todavía podemos suponer que la inclusión de niños económicamente activos de 10 a 13 años afecta de forma más significativa la comparación de la distribución según "categoría ocupacional» en las categorías de «trabajador familiar sin remuneración» y en los casos en los que no fue posible especificar su categoría. De modo que, si los excluimos, obtenemos la siguiente imagen (cuadro 2). Allí vemos que el porcentaje de «asalariados» se reduce en 1960 para volver a crecer en 1970, mientras que hay un crecimiento continuo de la

Cuadro 2. Distribución de la PEA según categoría ocupacional (modificada).

\begin{tabular}{lccccccc}
\hline & 1947 & 1960 & 1970 & 1980 & 1991 & 2001 & 2010 \\
\cline { 2 - 8 } Categoría ocupacional & \multicolumn{1}{c}{$\%$} & $\%$ & $\%$ & $\%$ & $\%$ & $\%$ & $\%$ \\
\hline Patrón o empresario & 16,7 & 13,0 & 6,2 & 6 & 7,5 & 6,4 & 6,81 \\
Cuenta propia & 6,9 & 12,7 & 17,5 & 20,1 & 24,2 & 21 & 19,1 \\
Asalariado & 76,4 & 74,4 & 76,3 & 74 & 68,3 & 72,6 & 74,0 \\
Total & 100,0 & 100,0 & 100,0 & 100,0 & 100,0 & 100,0 & 100,0 \\
\hline
\end{tabular}

Fuente: censos nacionales de población de 1947, 1960, 1970, 1980, 1991, 2001, 2010, INDEC, Argentina. 
Cuadro 3. Tasa de actividad.

\begin{tabular}{lrrrrrrc}
\hline & 1947 & 1960 & 1970 & 1980 & 1991 & 2001 & 2010 \\
\hline Tasa de actividad & $56,9 \%$ & $52,9 \%$ & $48,1 \%$ & $50,3 \%$ & $58,8 \%$ & $57,2 \%$ & $65,6 \%$ \\
\hline
\end{tabular}

Fuente: censos nacionales de población de 1947, 1960, 1970, 1980, 1991, 2001, 2010, INDEC, Argentina.

Cuadro 4. Evolución del porcentaje de asalariados en la industria y de asalariados por empleador. Comercio y servicios.

\begin{tabular}{lccccccc}
\hline & 1947 & 1960 & 1970 & 1980 & 1991 & 2001 & 2010 \\
\hline Asalariados industria & $77,7 \%$ & $74,9 \%$ & $81,6 \%$ & $80,8 \%$ & $71,2 \%$ & $72 \%$ & $73,8 \%$ \\
Asalariados por empleador. & 5,4 & 5,3 & 11,5 & 11,2 & 9,9 & 9,8 & 11,4 \\
Comercio y servicios & & & & & & & \\
\hline
\end{tabular}

Fuente: censos nacionales de población de 1947, 1960, 1970, 1980, 1991, 2001 y 2010, INDEC, Argentina.

Cuadro 5. Evolución del porcentaje de asalariados en la industria y de ocupados por establecimiento.

\begin{tabular}{lcccccc}
\hline & 1947 & 1964 & 1974 & 1985 & 1994 & 2004 \\
\hline Asalariados industria & $87,7 \%$ & $80,7 \%$ & $84,8 \%$ & $85 \%$ & $80,8 \%$ & $90,1 \%$ \\
Ocupado por establecimiento. & 2,4 & 2,5 & 4,4 & 2,8 & 1,7 & 3 \\
Comercio y servicios & & & & & & \\
\hline
\end{tabular}

Fuente: censos económicos de 1947, 1964, 1974, 1985, 1994 y 2004, INDEC, Argentina.

proporción de "cuentapropistas» y una caída de los «patrones». ¿Podemos considerar esos datos, al menos como tendencia, con cierta confianza? Los datos de industria y comercio tienen la ventaja de ofrecernos otro punto de referencia en los "censos económicos", aunque debemos tener en cuenta que la unidad de análisis de estos últimos es el "establecimiento» y no los «individuos». En los cuadros 4 y 5 se presenta la evolución del porcentaje de «asalariados» en la industria según los censos de población de 1947, 1960 y 1970 y según los censos económicos de 1947, 1964 y 1974. La evolución es similar, aunque difieren las proporciones de variación, mayor en el censo de población que en el censo económico. En los mismos cuadros vemos la proporción de asalariados por patrón en comercio y servicios según los censos de población, y los ocupados por establecimiento en comercio y servicios según los censos económicos. Nuevamente coinciden las tendencias de evolución en ambas fuentes. Es decir, es posible asumir que la evolución de la proporción de asalariados, patrones y cuentapropistas de los censos de población - excluyendo trabajadores familiares y trabajadores sin especificar categoría ocupacional - resulta una buena aproximación a sus tendencias, aunque sin considerar números absolutos ni porcentajes de variación.

En este sentido, las tendencias de evolución que observamos en el cuadro 2 son resultado del aumento absoluto de asalariados y de la caída absoluta de 
Cuadro 6. Porcentaje de asalariados + empleadores sobre categoría ocupacional y tasa de desempleo abierto.

\begin{tabular}{lccccccc}
\hline & 1947 & 1960 & 1970 & 1980 & 1991 & 2001 & 2010 \\
\hline $\begin{array}{l}\text { Asalariados + empleadores / } \\
\text { total categoría ocupacional }\end{array}$ & $89,9 \%$ & $82,2 \%$ & $76,5 \%$ & $77 \%$ & $70 \%$ & $75 \%$ & $78 \%$ \\
Tasa de desempleo abierto & $2,8 \%$ & $2,6 \%$ & $1,9 \%$ & Sin datos & $6,1 \%$ & $28,5 \%$ & $5,9 \%$ \\
\hline
\end{tabular}

Fuente: censos nacionales de población de1947, 1960, 1970, 1980, 1991, 2001 y 2010, INDEC, Argentina.

patrones (datos registrados en su tendencia por los censos de población y por los censos económicos), y de la tendencia continua al aumento absoluto y relativo de los cuentapropistas. Ello se expresa en el hecho de que la proporción de asalariados y patrones sobre el total de la "categoría ocupacional» —que en este caso es una aproximación a la proporción del espacio social ocupado por personificaciones de clase- se reduce a través de los tres censos (cuadro 6). Tenemos entonces un aumento cuantitativo de las personificaciones del trabajo - que se convierte también en aumento relativo a lo largo de la década del 60 y la primera mitad de la del 70-y una simultánea reducción de la proporción del espacio social ocupado por relaciones de clase.

Es un hecho reconocido en la literatura sobre clase y estratificación social en Argentina que el fenómeno del trabajo por cuenta propia tuvo hasta mediados de los años 70 un carácter muy diferente del que asumió desde 1976 en adelante (Torrado, 1994). En el período comprendido por los censos de 1947 y 1970, el crecimiento del cuentapropismo significó la expansión relativa de un espacio social mercantil no capitalista. Siguiendo con la imagen espacial podemos decir que este funcionó como una especie de "far west» sui generis, es decir, una posible salida individual de la relación salarial que puso un límite a las posibilidades de reducción de los salarios y de deterioro de las condiciones de trabajo, especialmente en aquellos sectores más expuestos a la competencia y la informalidad laboral como el de la construcción. Lejos de debilitar las capacidades estructurales para la acción colectiva de la clase obrera, las fortaleció. Esto en contraposición con el lugar funcional del cuentapropismo desde 1976 en adelante, momento a partir del cual significó crecientemente una porción de sobrepoblación relativa que debilita las capacidades estructurales de resistencia obrera.

A su vez, aunque los censos de población no son buenas fuentes para aproximarse a la realidad del desempleo, los bajos niveles de la tasa de desocupación y su tendencia levemente descendente hasta 1970 son indicativos de que no existía una tendencia al crecimiento del desempleo abierto (cuadro 6).

Ambas tendencias - la referida al trabajo por cuenta propia y la referida al desempleo abierto- señalan un debilitamiento de la sobrepoblación relativa como elemento de la composición de clase de los asalariados entre 1947 y 1970.

Respecto de los censos de población desde 1980, las mayores dificultades de comparabilidad las plantea el censo de 2001. Si bien no difiere en las defi- 
niciones conceptuales u operacionales, su realización en el marco de una crisis aguda y las deficiencias de los censos para captar con fidelidad la condición de actividad llevaron a una sobreestimación de la desocupación cuya causa principal fue la subestimación del trabajo informal, en particular del autoempleo, refugio incluido en la categoría de trabajador por cuenta propia. Ello debe haberse expresado en la distribución según categoría ocupacional. Pero también es posible que haya afectado la tasa de actividad, sobreestimando a los inactivos. La caída de la tasa de actividad en 2001 respecto de 1991 y el fuerte incremento en 2010 pueden ser explicados por esa razón (cuadro 3). ¿Hasta qué punto entonces podemos fiarnos de la evolución de la PEA según categoría ocupacional en un período tan central en nuestra investigación como lo es el período 1991-2010? Si tomamos el mismo criterio de comparación que elegimos para el período 1947-1970, la contrastación del porcentaje de asalariados dentro de la industria y del número de asalariados por establecimiento en comercio con los censos económicos, vemos nuevamente que para el período 1980-2010 coincide la evolución aunque no los números absolutos y porcentajes. Ello nos estaría indicando que es fiable tomar las tendencias de evolución para asalariados, pero en este caso la posible subestimación de los cuentapropistas en 2001 pone límites a las conclusiones que podemos sacar. Es más razonable tomar solo indicativamente los datos de 2001 y comparar de manera más fiable 2010 con 1991.

Asumiendo estos reparos, los cuadros 1 y 2 muestran dos subperíodos bien diferenciados. Uno entre 1970 y 1991, en el que tiende a caer la proporción de asalariados y a crecer la proporción de trabajadores por cuenta propia y patrones. El otro entre 1991 y 2010 , en que crece la proporción de asalariados hasta alcanzar los niveles de 1970, decrece el trabajo por cuenta propia y también decrece, aunque levemente, el porcentaje de patrones. Ello es consistente con un decrecimiento de la proporción de individuos que se enfrentan como personificaciones de clase entre 1970 y 1991 y su aumento entre 1991 y 2010 (cuadro 6).

Los datos disponibles en los censos del período 1980-2001 nos permiten profundizar el análisis de la estructuración de las relaciones sociales como relaciones de clase. Específicamente, las clasificaciones ocupacionales nos permiten distinguir, con mayor o menor precisión según los censos, a aquellos asalariados que cumplen funciones del capital (dirección y supervisión del proceso de acumulación) -y que por lo tanto se enfrentan simultáneamente como personificaciones del trabajo frente al capital y como personificaciones del capital frente al trabajo- de aquellos asalariados sin poder de mando, personificaciones del trabajo frente al capital. El resultado de ello es el de aproximarnos al espacio de las relaciones de clase como un espacio continuo, en el cual las fronteras entre lo que es y lo que no es clase obrera son borrosas y sujetas a su definición en el terreno de las luchas. Decimos aproximarnos porque en la medida que los datos están disponibles con cierto grado de agregación nos vemos obligados a establecer cortes más o menos arbitrarios entre categorías, lo que puede crear la sensación de que nos acercamos a una noción de clasificación. 
Cuadro 7.1. Esquema de operacionalización.

\begin{tabular}{lll}
\hline & Patrón & Asalariado \\
\hline Funciones del capital & $\begin{array}{l}\text { Propietarios de grandes empresas } \\
\text { Propietarios pymes }\end{array}$ & $\begin{array}{l}\text { Posiciones directivas de grandes } \\
\text { empresas y del Estado }\end{array}$ \\
& $\begin{array}{l}\text { Propietarios no liberados de funciones } \\
\text { del trabajo }\end{array}$ & $\begin{array}{l}\text { Posiciones directivas pymes } \\
\text { Jefes y supervisores }\end{array}$ \\
& Obreros y empleados sin mando \\
& Ejército industrial de reserva \\
\hline
\end{tabular}

Fuente: elaboración propia.

En el cuadro 7.1 ofrecemos el esquema de operacionalización —adecuado a los datos disponibles - de la noción de clase como relación social objetiva. Tenemos dos grandes dimensiones, por un lado, si de acuerdo a la "categoría ocupacional» se es patrón o asalariado, por otro lado, si de acuerdo al «carácter» y la «jerarquía de la ocupación» se ejercen o no funciones del capital. La gradación de colores pretende mostrar cómo entre los casos extremos (propietarios de grandes empresas y asalariados sin poder de mando o que forman parte del ejército industrial de reserva) existen una serie de posiciones de sujeto caracterizadas por el establecimiento de relaciones sociales que oponen a unos individuos frente a otros simultáneamente como personificaciones del capital

Cuadro 7.2. Distribución de los individuos según su posición en las relaciones de clase (1980).

\begin{tabular}{|c|c|c|c|c|c|c|}
\hline & & Patrón & Asalariado & Totales & & \\
\hline \multirow[t]{6}{*}{ Funciones del capital } & & $6.426(0,1 \%)^{(1)}$ & & & & \\
\hline & 172.1 & $37(2,3 \%)(2,2 \%)^{(2)}$ & & & & \\
\hline & & & $49.396(0,6 \%)^{(4)}$ & & & \\
\hline & & $388.546(5,1 \%)^{(3)}$ & No es posible diferenciarlos & & & \\
\hline & & & $214.237(2,8 \%)^{(5)}$ & & & \\
\hline & & & $6.673 .945(88,4 \%)(87,0 \%)^{(6)}$ & & & \\
\hline \multicolumn{3}{|l|}{ Nuevos trabajadores } & $44.608(0,6 \%)$ & & & \\
\hline \multirow{3}{*}{ Sin especificar } & & 567.109 & 6.982 .186 & 7.549 .295 & & \\
\hline & & 8.398 & 209.749 & 218.147 & & \\
\hline & & & & 7.767 .442 & $77,41 \%$ & ( $\%$ de la PEA) \\
\hline \multicolumn{3}{|c|}{ Cuenta propia descalificados } & $123.989(1,6 \%)$ & 7.891 .431 & $78,65 \%$ & ( $\%$ de la PEA) \\
\hline
\end{tabular}

(1) Patrones, ocupaciones directivas, establecimientos de más de 5 personas.

(2) Patrones, demás grupos de ocupación (excluidas las no especificadas), establecimientos de más de 5 personas.

(3) Patrones de establecimientos de menos de 5 personas.

(4) Asalariados en ocupaciones directivas de establecimientos del sector privado de más de 5 personas y altos funcionarios del Estado.

(5) Asalariados, jefes y supervisores y en ocupaciones directivas en establecimientos del sector privado de menos de 5 personas.

(6) Asalariados sin poder de mando.

Fuente: censo nacional de población de 1980, INDEC, Argentina. 
Cuadro 7.3. Distribución de los individuos según su posición en las relaciones de clase (1991).

\begin{tabular}{lrrrr}
\hline \multicolumn{1}{c}{ Patrón } & \multicolumn{1}{c}{ Asalariado } & Totales \\
\hline Funciones del capital & $29.796(0,3 \%)^{(1)}$ & & \\
& $157.306(1,8 \%)(1,6 \%)^{(2)}$ & $92.835(1,1 \%)(1 \%)^{(4)}$ & \\
& & $8.327(0,1 \%)^{(5)}$ & \\
& $584.820(6,8 \%)(6,1 \%)^{(3)}$ & $251.936(2,9 \%)(2,6 \%)^{(6)}$ & \\
Desocupados & $6.648 .886(77,3 \%)(69,7 \%)^{(7)}$ & \\
Totales & $833.872(9,7 \%)(8,7 \%)$ & \\
Sin especificar & 187.102 & 7.832 .088 & 8.604 .010 & \\
& 100.997 & 978.323 & 1.079 .320 & \\
Cuenta propia descalificados & & 9.683 .330 & $70,67 \%$ & (\% de la PEA) \\
\hline
\end{tabular}

(1) Patrones en ocupaciones directivas de grandes empresas.

(2) Patrones en ocupaciones directivas de pymes, jefes, supervisores y capataces menos patrones en establecimientos de menos de 5 personas.

(3) Patrones de establecimientos de menos de 5 personas.

(4) Asalariados en ocupaciones directivas de grandes empresas, organizaciones sociales y altos funcionarios del Estado.

(5) Asalariados en ocupaciones directivas de medianas empresas.

(6) Asalariados jefes, supervisores y capataces.

(7) Asalariados sin poder de mando.

Fuente: censo nacional de población de 1991, INDEC, Argentina.

y del trabajo (propietarios de pymes que solo ejercen parcialmente las funciones del capital, las que tendencialmente son subsumidas formalmente al poder de los propietarios de grandes empresas; propietarios que no se han liberado de las funciones del trabajo - ejecución-; asalariados que ocupan posiciones directivas en grandes empresas; asalariados que ocupan posiciones directivas en pymes; jefes y supervisores).

En los cuadros 7.2 al 7.4 se presentan los datos construidos para los censos nacionales de población de 1980, 1991 y 2001.

De su lectura surgen una serie de conclusiones relevantes. En primer lugar, el crecimiento porcentual de los patrones entre 1980 y 1991, de acuerdo a la distribución según categoría ocupacional, parece ser un efecto del aumento del desempleo. Cuando incluimos a los desocupados entre las personificaciones de clase obrera, el porcentaje de patrones entre ambos censos varía muy levemente y lo que se observa es un aumento del peso de los propietarios no liberados de funciones del trabajo (patrones de establecimientos con menos de cinco trabajadores). Entre 1991 y 2001, en cambio, se produce una caída del porcentaje de patrones, explicada por la disminución relativa de patrones pymes y patrones no liberados de funciones del trabajo. Lo que se expresa en estas tendencias es, por lo tanto, un estancamiento de los patrones entre 1980 y 1991 y una agudización de las tendencias a la centralización del capital entre 1991 y 2001.

En segundo lugar, a pesar de los cambios en la clasificación de ocupaciones que afectan la comparabilidad de las diferentes categorías de asalariados que cum- 
Cuadro 7.4. Distribución de los individuos según su posición en las relaciones de clase (2001).

\begin{tabular}{lrrrr}
\hline & \multicolumn{1}{l}{ Patrón } & \multicolumn{1}{c}{ Asalariado } & \multicolumn{1}{c}{ Totales } \\
\hline Funciones del capital & $22.249(0,2 \%)^{(1)}$ & & \\
& $100.030(0,8 \%)^{(2)}$ & $98.801(0,8 \%)^{(4)}$ & \\
& & $29.767(0,2 \%)^{(5)}$ & & \\
& $558.475(4,6 \%)^{(3)}$ & No es posible diferenciarlos & & \\
& & & \\
Desocupados & $6.913 .586(57,2 \%)(56,7 \%)^{(6)}$ & & \\
Totales & $4.351 .596(36,0 \%)(35,7 \%)$ & & \\
Sin especificar & 680.754 & 11.393 .750 & 12.074 .504 & \\
& 0 & 318.660 & 318.660 & \\
Cuenta propia descalificados & & 12.393 .164 & $81,19 \%$ & (\% de la PEA) \\
\hline
\end{tabular}

(1) Patrones en ocupaciones directivas de grandes empresas.

(2) Patrones en ocupaciones directivas de pymes, jefes, supervisores y capataces menos patrones en establecimientos de menos de 5 personas.

(3) Patrones de establecimientos de menos de 5 personas.

(4) Asalariados en ocupaciones directivas de grandes empresas, organizaciones sociales y altos funcionarios del Estado.

(5) Asalariados en ocupaciones directivas de pequeñas y medianas empresas.

(6) Demás categorías de asalariados.

Fuente: censo nacional de población de 2001, INDEC, Argentina.

plen funciones del capital, los resultados son suficientes para concluir que, para el período considerado, representan una magnitud cuantitativamente irrelevante. En tercer lugar, la tendencia a la disminución del espacio social ocupado por personificaciones de clases (\% de la PEA) entre 1980 y 1991, cuando excluimos a todos los trabajadores por cuenta propia $(77,4 \%$ a $70,6 \%)$, prácticamente desaparece cuando se incluye a los trabajadores por cuenta propia descalificados como parte de la clase obrera $(78,6 \%$ a $77,4 \%)$. Estos datos fortalecen la hipótesis de que debe incluirse a esta categoría como parte de la sobrepoblación relativa y, en particular, del ejército industrial de reserva en lugar de interpretar su crecimiento como expresión de un proceso de desproletarización. Asimismo, entre 1991 y 2001 se observa un aumento del espacio social ocupado por personificaciones de clase $(77,4 \%$ a $82 \%$ de la PEA) cuando incluimos a los desocupados - los que, como hemos señalado, incluyen en el censo de 2001 un número indeterminado de trabajadores por cuenta propia descalificados y asalariados precarios de ocupación intermitente- $-\mathrm{y}$ a los trabajadores por cuenta propia descalificados.

En cuarto lugar, la incorporación de los desocupados y de los trabajadores por cuenta propia entre las personificaciones de clase también revela una mayor continuidad entre 1980 y 1991 en cuanto al peso de los asalariados (92,6 \% de las personificaciones de clase en 1980 y $91,8 \%$ en 1991) y un cierto crecimiento entre 1991 y el 2001 (94,4\% en 2001).

Lo que muestran las conclusiones tercera y cuarta es, antes que una reducción del peso estructural de la clase obrera, una fuerte mutación en su com- 
Cuadro 8. Asalariados según tamaño del establecimiento.

\begin{tabular}{|c|c|c|c|c|c|c|}
\hline \multicolumn{7}{|c|}{ Tamaño del establecimiento } \\
\hline & \multicolumn{3}{|c|}{1980} & \multicolumn{3}{|c|}{1991} \\
\hline & $\begin{array}{c}\text { Hasta } 5 \\
\text { asalariados }\end{array}$ & $\begin{array}{l}\text { Más de } 5 \\
\text { asalariados }\end{array}$ & Total & $\begin{array}{c}\text { Hasta } 5 \\
\text { asalariados }\end{array}$ & $\begin{array}{l}\text { Más de } 5 \\
\text { asalariados }\end{array}$ & Total \\
\hline Número de asalariados & 1.275 .395 & 3.260 .147 & 4.535 .542 & 1.426 .493 & 2.721 .402 & 4.147 .895 \\
\hline \multirow[t]{3}{*}{ Porcentaje de asalariados } & $28,1 \%$ & $71,9 \%$ & $100 \%$ & $34,4 \%$ & $65,6 \%$ & $100 \%$ \\
\hline & \multicolumn{3}{|c|}{2001} & \multicolumn{3}{|c|}{2010} \\
\hline & $\begin{array}{c}\text { Hasta } 5 \\
\text { asalariados }\end{array}$ & $\begin{array}{c}\text { Más de } 5 \\
\text { asalariados }\end{array}$ & Total & $\begin{array}{c}\text { Hasta } 5 \\
\text { asalariados }\end{array}$ & $\begin{array}{c}\text { Más de } 5 \\
\text { asalariados }\end{array}$ & Total \\
\hline Número de asalariados & 2.384 .798 & 2.956 .038 & 5.340 .836 & 3.923 .193 & 5.296 .614 & 9.219 .807 \\
\hline Porcentaje de asalariados & $44,6 \%$ & $55,4 \%$ & $100 \%$ & $42,6 \%$ & $57,4 \%$ & $100 \%$ \\
\hline
\end{tabular}

Fuente: censos de población de 1980, 1991, 2001, 2010, INDEC, Argentina.

posición de clase. Este cambio abarca un amplio conjunto de dimensiones. La que aquí se evidencia es una señalada por diversos autores (Iñigo Carrera et al., 2012; Donaire et al., 2018): la tendencia al crecimiento de la sobrepoblación relativa. Si esta ya se advierte entre los censos de 1980 y 1991, es especialmente importante entre 1991 y 2001. La suma de desocupados y trabajadores por cuenta propia descalificados arroja un salto desde el 18,4\% de las personificaciones de clase $-20,9 \%$ de los asalariados sin mandoen 1991 a un 36,7 \% de las personificaciones de clase - 39,3\% de los asalariados sin mando - en 2001. Dados los problemas de comparabilidad entre estos dos censos y las limitaciones de las fuentes censales para medir este fenómeno, estos deben considerarse solo datos indicativos, aquí no se contabilizan, por ejemplo, el subempleo horario y formas de sobrepoblación relativa latente como las existentes en el campo y en los distintos niveles del Estado.

Los cambios en las tendencias de la composición de clase de los trabajadores se pueden advertir también en la evolución de la distribución de los asalariados por tamaño del establecimiento y según calificación de la ocupación.

La distribución de los asalariados por establecimiento solo está disponible para los censos nacionales de población desde 1980. Como podemos observar en el cuadro 8, los asalariados que trabajan en establecimientos de menos de cinco trabajadores, lo que constituye un indicador de informalidad laboral, pasan del $28,1 \%$ en 1980 a un $42,6 \%$ en 2010 , con un pico del $44,6 \%$ en 2001. Si bien no podemos comparar los datos con el censo de 1970, la evolución es consistente con la hipótesis de una mutación en la composición de clase desde 1976 y evidencia un sendero de dualización de la fuerza laboral desde 1991.

La evolución de la distribución de los asalariados según calificación muestra tendencias consistentes que permiten una interpretación conceptual de los datos, a pesar de la comparabilidad limitada de los clasificadores ocupacionales 
Cuadro 9. Asalariados según calificación.

\begin{tabular}{|c|c|c|c|c|c|c|}
\hline & \multicolumn{2}{|c|}{1960} & \multicolumn{2}{|c|}{1970} & \multicolumn{2}{|c|}{1980} \\
\hline & $\mathrm{N}$ & $\%$ & $\mathrm{~N}$ & $\%$ & $\mathrm{~N}$ & $\%$ \\
\hline C. profesional & 439.295 & $9,06 \%$ & 585.550 & $9,58 \%$ & 209.273 & $3,02 \%$ \\
\hline C. técnica & & & & & 599.838 & $8,65 \%$ \\
\hline C. operativa & 4.406 .857 & $90,94 \%$ & 5.528 .850 & $90,42 \%$ & 4.592 .074 & $66,19 \%$ \\
\hline Descalificados & & & & & 1.536 .393 & $22,15 \%$ \\
\hline Sin especificar & 344.368 & & 266.100 & & 209.749 & \\
\hline \multirow[t]{3}{*}{ Total } & 4.846 .152 & $100,00 \%$ & 6.114 .400 & $100,00 \%$ & 6.937 .578 & $100,00 \%$ \\
\hline & & 1991 & & & 2001 & \\
\hline & $\mathrm{N}$ & $\%$ & $\%$ & $\mathrm{~N}$ & $\%$ & $\%$ \\
\hline C. profesional & 309.487 & $4,46 \%$ & $19,98 \%$ & 474.588 & $6,77 \%$ & $24,79 \%$ \\
\hline C. técnica & 1.077 .567 & $15,52 \%$ & & 1.263 .164 & $18,02 \%$ & \\
\hline C. operativa & 3.252 .716 & $46,85 \%$ & $80,02 \%$ & 3.290 .169 & $46,95 \%$ & $75,21 \%$ \\
\hline Descalificados & 2.302 .419 & $33,17 \%$ & & 1.980 .637 & $28,26 \%$ & \\
\hline Sin especificar & 208.108 & & & 657.335 & & \\
\hline Total & 6.942 .189 & $100,00 \%$ & & 7.008 .558 & $100,00 \%$ & \\
\hline
\end{tabular}

Fuente: censos de población de 1960, 1970, 1980, 1991, 2001, INDEC, Argentina.

de los censos. ${ }^{6}$ Los datos del cuadro 9 muestran una tendencia de largo plazo al aumento de la proporción de asalariados de calificación técnica y profesional y a una caída correlativa de los asalariados de calificación operativa y descalificados. Sin embargo, entre 1960 y 1970 las variaciones son leves, mientras que desde 1980 la tendencia se profundiza dando lugar a modificaciones significativas en la composición de clase según calificación. Además, a pesar de cierta reversión entre 1991 y 2001, se observa una caída tendencial de la proporción de asalariados con calificación operativa y un aumento de la proporción de descalificados. Entre 1960 y 1970, por lo tanto, parece haber cierta estabilidad en la distribución de los asalariados según calificación con un claro predominio — más del 90 \% de los casos- de ocupaciones de calificación operativa y sin calificación. Desde 1980, el aumento del peso de los técnicos y profesionales y la simultánea reducción relativa de los asalariados de calificación operativa evidencia una tendencia a la polarización de las calificaciones.

El aumento de la sobrepoblación relativa, la dualización entre formales e informales y la polarización de las calificaciones señalan la tendencia a una heterogeneización de la fuerza laboral que debilita las capacidades estructurales para la organización de la acción colectiva de clase. Esto en contraposición con el debilitamiento de la sobrepoblación relativa, la relativa estabilidad de la estructura de calificaciones y el peso abrumador de las calificaciones operativas y de las ocupaciones sin calificación que observamos hasta 1970.

6. Especialmente, los cambios a partir de 1991 vuelven en un sentido estricto indicativas las tendencias de evolución que se muestran en el cuadro 9. 
Cuadro 10. Medidas de tendencia central para fuerza motriz (HP) por asalariado.

\begin{tabular}{lccccc}
\hline & 1947 & 1954 & 1964 & 1974 & 1985 \\
\hline Promedio ponderado & 1,9 & 3,2 & 4,6 & 5,1 & 8,3 \\
Desviación estándar ponderada & 1,60 & 1,68 & 2,21 & 2,65 & 4,60 \\
Coeficiente de variación & 0,83 & 0,52 & 0,48 & 0,52 & 0,55 \\
Asimetría de Fisher & 7,57 & 1,90 & 2,08 & 3,8 & 1,75 \\
Curtosis & 83,1 & 8,65 & 11,92 & 26,64 & 5,25 \\
\hline
\end{tabular}

Fuente: censos económicos de 1947, 1964, 1970, 1985, INDEC, Argentina.

Cuadro 11. Medidas de tendencia central para consumo intermedio/salarios.

\begin{tabular}{llccc}
\hline & 1974 & 1985 & 1994 & \multicolumn{1}{c}{2004} \\
\hline Promedio ponderado & 4,1 & 4,0 & 4,9 & 8,22 \\
Desviación estándar ponderada & 2,08 & 2,77 & 2,32 & 4,81 \\
Coeficiente de variación & 0,50 & 0,70 & 0,47 & 0,58 \\
Asimetría de Fisher & 1,85 & 5,61 & 4,34 & 2,78 \\
Curtosis & 5,46 & 33,67 & 24,62 & 11,65 \\
\hline
\end{tabular}

Fuente: censos económicos de 1974, 1985, 1994, 2004, INDEC, Argentina.

Cuadro 12. Medidas de tendencia central para salario por asalariado.

\begin{tabular}{lrrrrrrr}
\hline & 1947 & 1954 & 1964 & 1974 & 1985 & 1994 & 2004 \\
\hline Coeficiente de variación & 0,15 & 0,16 & 0,16 & 0,19 & 0,25 & 0,28 & 0,42 \\
Asimetría de Fisher & 0,69 & $-0,67$ & 0,33 & 0,34 & 0,48 & 1,07 & 2,54 \\
Curtosis & 4,72 & 5,30 & 11,93 & 0,84 & $-0,53$ & 2,18 & 8,41 \\
\hline
\end{tabular}

Fuente: censos económicos de 1947, 1964, 1974, 1985, 1994, 2004, INDEC, Argentina.

Estas conclusiones son reforzadas si recurrimos a algunos datos de los censos económicos entre 1947 y 2004. Si bien los censos económicos presentan dificultades comparativas similares a las de los censos de población, la restricción a la industria permite reducirlas dentro de ciertos parámetros. Por otra parte, la industria es, en el período, el núcleo dinámico de una serie de transformaciones que afectan las tendencias de la composición de clase del conjunto de los asalariados. En este sentido, en los cuadros 10, 11 y 12 vemos una serie de indicadores que buscan ser una aproximación a las tendencias de evolución de la composición de clase en la industria. Aunque no generalizables al conjunto de la clase obrera, puede considerarse que constituyen tendencias profundas que se refractan en el resto de los sectores, a los que provisoriamente dejamos de lado. ${ }^{7}$

7. La utilización de medidas ponderadas — requerida por la agregación de los datos en los cuadros publicados de los censos - supuso dejar de lado el análisis de la heterogeneidad intrarrama. Dicha exclusión es relevante en la década del 60 en aquellas ramas donde se insertó el capital extranjero y prácticamente en todas las ramas durante la década del 90. En cambio, la utilización del clasificador industrial del censo económico de 1947 supuso ciertas diferencias insalvables de clasificación pero cuantitativamente poco significativas. 
En primer lugar, en el cuadro 10, mostramos una serie de medidas de tendencia central para la evolución de la fuerza motriz, medida en caballos de fuerza (HP), por obrero. Esta variable es un indicador de la evolución de la «composición técnica de clase», de su grado de socialización (Tronti, 2001; Negri, 2001). Si observamos el promedio ponderado, vemos que este crece a lo largo de los censos, con excepción de $1985 .{ }^{8}$ El coeficiente de variación nos indica que la heterogeneidad entre ramas después de reducirse entre 1947 y 1964 tiende a crecer levemente en 1974. El coeficiente de asimetría y de curtosis nos permiten componer la imagen de cómo evoluciona la distribución de los establecimientos según su fuerza motriz por obrero para el período del que disponemos datos. En ese sentido, después de un movimiento en dirección contraria entre 1947 y 1954, desde 1954 la distribución de los establecimientos tiende a sesgarse más hacia la derecha de la media, es decir, hacia los establecimientos con mayor fuerza motriz por obrero, y a concentrarse más en los valores más cercanos al vértice y la base de la pirámide.

Dado que desde 1994 los censos económicos dejaron de relevar la fuerza motriz instalada, tomamos como variable proxy para reconstruir el resto del período el consumo intermedio dividido por los salarios pagados (cuadro 11). ${ }^{9}$ El promedio ponderado crece a lo largo de todo el período, pero sobre todo entre 1994 y 2004. El coeficiente de variación vuelve a mostrar una tendencia al leve crecimiento de la heterogeneidad. Sin embargo, debemos recordar que aquí se trata de la heterogeneidad entre ramas, y que el proceso de heterogeneización intrarrama del grado de socialización del trabajo, presumiblemente importante en un proceso de reestructuración, queda invisibilizado. Lo mismo cabe para la asimetría y la curtosis cuyos sesgos crecen respecto de 1974 — sesgo hacia los valores extremos a la derecha de la media y mayor «picudez»— a pesar de la disminución entre 1994 y 2004.

Pero aun más interesante resulta la evolución de las medidas de tendencia central para el salario por asalariado (cuadro 12). El coeficiente de variación, en oposición a las otras variables, casi no varía entre 1947 y 1964, aunque crece levemente en 1974. Esta mirada resulta potenciada por la evolución de los sesgos. La evolución del coeficiente de asimetría muestra valores muy poco sesgados respecto de la curva normal para el período 1947-1974 y con tendencia descendente. En el caso de la curtosis, la tendencia es más oscilante. Se evidencia, por lo tanto, la reproducción de una distribución homogénea de los establecimientos según salario por asalariado. En contraposición, la evolución desde 1980 da cuenta de una creciente heterogeneidad medida según el coeficiente de variación y de un aumento de los sesgos de distribución, debido

8. El censo económico de 1985 muestra el impacto de la caída del PBI desde 1975. Dado que el personal ocupado, en períodos de crisis, varía más que la fuerza motriz instalada, es probable la sobreestimación de la variable. Por ello, limitamos el análisis al período 1947-1974.

9. Dado que el consumo de materias primas en los períodos de crisis varía más que el personal ocupado, excluimos 1985. Fuerza motriz por obrero y consumo intermedio sobre salarios arrojan en 1974 resultados similares en todas las medidas consideradas; sobre esta base es que, con las limitaciones del caso, asumimos que podemos empalmar ambas series. 
al peso de los valores extremos a la derecha de la media - lo que supone a su vez concentración de casos en los valores debajo de la media - según la evolución del coeficiente de asimetría y aumento del grado de «picudez» medido por la curtosis.

Las diferencias de evolución entre los indicadores del «grado de socialización» y de "heterogeneidad salarial» —es decir, en la medida que nos desplazamos desde la composición técnica hacia la composición política de clase, en cuanto eso es posible en un análisis de estructura de clases- dan cuenta del tipo de relación entre estructura de clase y relaciones de fuerza entre clases. La estructura de clases desde una perspectiva marxista no es más que: 1) la distribución de los individuos como nudos/personificaciones de relaciones sociales de clase en un momento dado; 2) un índice del grado de composición (técnica) del obrero colectivo, como momento subjetivo de la relación de capital. Por lo tanto, desde una perspectiva diacrónica, no es más que la condensación de relaciones de fuerza sociales entre clases que son reproducidas por la acumulación de capital como su fundamento. Es resultado de relaciones de fuerza y, a su vez, determinación de capacidades estructurales de organización y lucha, las que se ponen en juego en el espacio de los enfrentamientos sociales como momento de la constitución de sujetos colectivos tendencialmente políticos. Es desde esta perspectiva que la estructura de clases puede ser considerada como primer momento de las relaciones de fuerza sociales entre clases.

Por ello, en este breve recorrido nos movimos desde la distribución de individuos como personificaciones de relaciones de clase hacia atributos crecientemente colectivos que intentaron dar cuenta de la composición de clase de los asalariados, de su constitución objetiva como realidad colectiva y no como clasificación de individuos según atributos sociales.

El resultado para el período 1947-1974 es el de un incremento absoluto de las personificaciones del trabajo, un debilitamiento de la sobrepoblación relativa - por efecto del carácter del trabajo por cuenta propia y del bajo desempleo abierto- y una conservación e incremento de la homogeneidad de su composición en el marco de un proceso de aumento de su grado de socialización. Los datos desde 1974, por el contrario, muestran una tendencia a la heterogeneización de la composición de clase en el marco de una tendencia al aumento de la sobrepoblación relativa que, de conjunto, tiende a debilitar las capacidades estructurales para la organización de la acción colectiva de los trabajadores. Sin embargo, la evolución de las variables consideradas desde 1980 también exige una subperiodización. Si entre 1974 y 1991 parece haber un estancamiento de las personificaciones del trabajo y del espacio estructural ocupado por las relaciones de clase, desde 1991 es evidente un proceso de proletarización en el marco del cual se agudizan las tendencias a la heterogeneización de la composición de clase y al aumento de la sobrepoblación relativa.

Veamos sumariamente qué significado adquieren esos datos cuando se los inscribe en la periodización y tendencias del modo de acumulación a los que referimos brevemente en la segunda sección de este trabajo. Allí señalábamos que las principales discusiones sobre las características y la periodización del 
modo de acumulación en Argentina se concentran en el período posterior a 1976. En este sentido, la evolución de las variables seleccionadas parece ser consistente con la periodización adoptada.

Empecemos por ciertos aspectos de la evolución de las variables en el período ISI. Efectivamente ciertos matices entre la evolución de los datos entre 1960 y 1970 y entre 1964 y 1974, en contraposición con el período comprendido entre 1947 y 1960/64, abonan la tesis de que debe distinguirse el subperíodo 1964-1974 del subperíodo 1945-1963 (Basualdo, 2006): leve tendencia a la heterogeneización de la industria según composición técnica del capital (cuadro 10), leve tendencia a la heterogeneización salarial (cuadro 12), leve incremento relativo de los asalariados con calificación técnica y/o profesional (cuadro 9), incremento del número de asalariados en relación a patrones y trabajadores por cuenta propia en la industria y de los ocupados por establecimiento en comercio y servicios (cuadros 4 y 5). Todo ello es compatible con cierta tendencia a la reestructuración que, como afirma el conjunto de la literatura sobre la economía del período, tuvo su epicentro en la creciente presencia del capital extranjero en la estructura productiva local. Sin embargo, los resultados limitados de dicha reestructuración son también consistentes con la continuidad esencial de la tendencia a la homogeneización de la clase obrera. El tipo de dualización de la estructura económica que caracterizó a la ISI en Argentina — que tendió a coincidir con la oposición ciudad/campo- dio lugar a esa dinámica homogeneizadora del trabajo urbano, cuyas tendencias de desarrollo tenían su núcleo en la acumulación de capital en la industria.

La tendencia a la heterogeneización del trabajo urbano desde 1976 es consistente con la existencia de un proceso de reestructuración en curso desde el golpe militar de ese año. Sin embargo, la comparación de los censos desde 1970 hasta 2010 y de los censos económicos desde 1974 hasta 2004 apunta a la necesidad de distinguir los períodos 1976-1989 y 1989-2010. Por un lado, la tendencia a la estabilización del peso de los patrones y de los asalariados en la estructura de clases entre 1980 y 1991 (ver cuadros 7.1 al 7.4) es compatible con un período de reestructuración productiva bloqueada, estancamiento y/o caída del PBI y más en general de ausencia de desarrollo capitalista. Mientras que las tendencias desde 1991 a la proletarización, a la caída relativa del número de patrones (más aún en un contexto de aumento de su número absoluto) y a la profundización de la heterogeneización de la composición de clase de los trabajadores son indicadores consistentes con el despliegue de un proceso de reestructuración productiva, de crecimiento económico basado en la acumulación de capital productivo y de desarrollo capitalista dependiente. Respecto del período posterior a la crisis de 2001, si bien se observan ciertos cambios de tendencias - caída del desempleo (cuadro 6), leve baja en el porcentaje de asalariados en establecimientos de menos de cinco trabajadores (cuadro 8) que son consistentes con cierta recomposición de la clase trabajadora, aun en esos casos los cambios no revierten los efectos de la reestructuración de los años 90 y se observan fuertes continuidades en todas las tendencias centrales de la evolución de la estructura de clases y de la composición de la clase 
obrera. Nuevamente, los datos son consistentes con la consideración de la posconvertibilidad como un subperíodo del período abierto en 1989. El tipo de dualización de la estructura económica que tiende a producir el proceso de acumulación de capital desde 1989 atraviesa campo y ciudad creando una creciente heterogeneización del trabajo urbano.

\section{Una aproximación al análisis empírico desde la perspectiva sociológica}

Como decíamos antes, mientras que la "noción marxista» de clase es la de una relación social objetiva que supone una modalidad específica de subjetivación, las clases sociológicas son distribuciones y clasificaciones de los individuos según atributos significativos. Su principal objetivo es determinar/predecir chances diferenciales de vida de los individuos a partir de su posición en dicha distribución (situación de clase). También señalábamos que la capacidad predictiva de los modelos será mayor cuanto más significativos sean los atributos seleccionados para identificar el modo desigual en que la contradicción capital/ trabajo — la libertad/coacción que articula la relación salarial— estructura la vida de las personas.

La razón del buen desempeño de los modelos inspirados en el trabajo de Goldthorpe (Goldthorpe y Mcknigth, 2004), al menos en los países centrales, es que tienen como dimensión principal la «relación de empleo» que mide de manera bastante adecuada la distribución de los individuos según probabilidades de despido/empleabilidad, las que están asociadas a todo un rango de asignación de probabilidades de vida individuales. Algo similar ocurre con los trabajos de Wrigth. Wright trabaja en el marco de la tradición marxista y, por lo tanto, busca fundar la estructura de clases en la relación de explotación. Sin embargo, su aproximación al problema de las clases es sociológica, ya que parte de la distinción entre individuos y estructura de posiciones. Por lo tanto, el problema principal es el de la clasificación de los individuos, y la eficacia del modelo se juega en su capacidad predictiva de probabilidades de vida. Wright clasifica a los individuos según la relación de propiedad (jurídica) sobre los medios de producción, la posición en la jerarquía de autoridad en la empresa capitalista y la posesión de habilidades (skills) escasas y/o conocimiento especializado (expertise) (Wrigth, 1997; 2015). Propiedad, autoridad y habilidades escasas/conocimiento especializado son transformados así en recursos (assets) de los que los individuos disponen en la circulación y en la producción. La distribución de los individuos en clases según la posesión o exclusión de cada uno de ellos implica distintos márgenes objetivos de libertad de acción que permiten establecer probabilidades típicas de vida.

Las particularidades del proceso de acumulación y del mercado de trabajo en Argentina obligan, sin embargo, a construir modelos adecuados a ellas. Aquí proponemos de modo exploratorio un modelo de siete estratos que busca describir lo más adecuadamente posible la distribución de los individuos según sus «márgenes de libertad de acción» tal como han sido definidos. Pero se ha debido tomar en cuenta también la disponibilidad de datos en las fuentes 
Cuadro 13. Esquema de siete estratos.

\begin{tabular}{|c|c|}
\hline Estrato & Descripción \\
\hline Estrato 1 & $\begin{array}{l}\text { Propietarios de grandes y medianas empresas. Ocupaciones directivas de grandes } \\
\text { y medianas empresas. Ocupaciones directivas del Estado. Profesionales (en función } \\
\text { específica) con categoría ocupacional de patrón. }\end{array}$ \\
\hline Estrato 2 & $\begin{array}{l}\text { Profesionales (en función específica) con categoría ocupacional de asalariados o de } \\
\text { trabajador por cuenta propia. }\end{array}$ \\
\hline Estrato 3 & $\begin{array}{l}\text { Propietarios de pequeños establecimientos (hasta } 5 \text { trabajadores). Trabajadores por } \\
\text { cuenta propia con calificación técnica u operativa. }\end{array}$ \\
\hline Estrato 4 & Asalariados con calificación técnica. \\
\hline Estrato 5 & Asalariados con calificación operativa. \\
\hline Estrato 6 & Asalariados no calificados. \\
\hline Estrato 7 & Trabajadores por cuenta propia no calificados. \\
\hline
\end{tabular}

Fuente: elaboración propia.

censales. El modelo está construido a partir de los criterios de propiedad de los medios de producción, autoridad y calificación. Se ha dejado de lado, sin embargo, la distinción manual/no manual, como también lo hace Salvia en su modelo de estratificación socioocupacional (Salvia y Quartulli, 2011). Esto diferencia este esquema de los modelos clásicos de estratificación social en Argentina (Germani, 1955; Torrado, 1994) y de algunos de los utilizados en investigaciones actuales (Jorrat, 2005; Dalle, 2016; Sacco, 2016). Diversos estudios han mostrado que esta dimensión tendió a perder significación, por lo menos desde los años 70. En América Latina algunos trabajos afirman que la distinción manual/no manual de nivel bajo ha perdido relevancia para explicar la diferencia de ingresos (Franco et al., 2011). Pablo Dalle, en su estudio sobre movilidad individual en Argentina entre 1960 y 2013, señala que las fronteras entre asalariados manuales y no manuales se tornan borrosas para trabajadores provenientes de la clase popular calificada (Dalle, 2016), conclusiones coincidentes con el planteo de Kessler y Espinosa de una ruptura de las barreras entre ambas categorías (Kessler y Espinosa, 2007). Todo apunta a que la transformación de los procesos de trabajo y la expansión de los servicios han tendido a simplificar y a rutinizar gran parte de las tareas no manuales, volviendo más significativa la distinción de calificaciones que el carácter manual o no manual de las ocupaciones.

En el cuadro 13 se presenta el esquema de siete estratos, de cuya agregación surge un esquema de tres clases (cuadro 14). La inclusión del estrato 5 (asalariados con calificación operativa) en la clase popular se debe a que aquí predominan obreros fabriles y trabajadores no manuales con tareas rutinarias, aunque sin duda, en términos de sus comportamientos y representaciones, es posible encontrarlos ora cerca de la clase media, ora cerca de los estratos 6 y 7 . Pasa lo mismo desde el punto de vista de la movilidad individual. De acuerdo al trabajo antes citado de Dalle, la de los asalariados calificados manuales y no manuales parece ser una región de frontera entre no calificados y asalariados 
Cuadro 14. Esquema de tres clases

\begin{tabular}{ll}
\hline Clase & Descripción \\
\hline Clase alta & Estrato 1 \\
Clase media & Estratos 2,3 y 4 \\
Clase popular & Estratos 5,6 y 7 \\
\hline
\end{tabular}

Fuente: elaboración propia.

con calificación técnica. Ello se debe a que las clases medias no constituyen un fenómeno objetivo-estructural. Si bien cierta capacidad diferencial para competir en el mercado de trabajo - lo que tiene efectos, entre otras variables, en el tipo de empleo, los ingresos y el grado de control y autonomía en el proceso de trabajo- oficia como condición de posibilidad de la construcción de modos de pensar, sentir y actuar comunes, la clase media es ante todo un fenómeno sociopolítico y cultural (Piva, 2014). Por contraste con la «clase marxista», relación social objetiva e independiente del modo en el que los sujetos se la representen, aquí —en la cuestión de la existencia de la clase media- la "conciencia» lo es todo.

Dados los fines exploratorios, las conclusiones son centralmente descriptivas. La productividad del esquema propuesto debe ponerse a prueba en el futuro a través del testeo de su eficacia para predecir probabilidades diferenciales de vida entre los individuos en términos de ingresos, movilidad social, etcétera. A su vez, dadas las limitaciones de las fuentes en términos de su comparabilidad, hemos construido datos para los censos de 1980, 1991 y 2001.

En el cuadro 15 podemos ver los resultados de la aplicación del modelo de siete estratos a dichos censos. Los datos, sin embargo, presentan algunas dificultades para su comparación. En primer lugar, en el censo de 1980 hemos debido reunir a trabajadores especializados junto a empleados y vendedores para intentar reconstruir la categoría de asalariados con calificación operativa.

Cuadro 15. Evolución de estratificación social en Argentina entre 1980 y 2001. Esquema de siete estratos.

\begin{tabular}{|c|c|c|c|c|c|c|}
\hline \multirow[b]{2}{*}{ Estrato 1} & \multicolumn{2}{|c|}{1980} & \multicolumn{2}{|c|}{1991} & \multicolumn{2}{|c|}{2001} \\
\hline & 195.498 & $2,0 \%$ & 295.135 & $2,8 \%$ & 306.614 & $3,1 \%$ \\
\hline Estrato 2 & 249.902 & $2,6 \%$ & 329.394 & $3,1 \%$ & 579.986 & $5,9 \%$ \\
\hline Estrato 3 & 2.297.993 & $23,7 \%$ & 2.570 .316 & $24,0 \%$ & 2.261 .497 & $23,1 \%$ \\
\hline Estrato 4 & 599.838 & $6,2 \%$ & 967.166 & $9,0 \%$ & 1.263 .164 & $12,9 \%$ \\
\hline Estrato 4 bis & 209.014 & $2,2 \%$ & 242.431 & $2,3 \%$ & & \\
\hline Estrato 5 & 4.383 .060 & $45,2 \%$ & 2.993 .407 & $27,9 \%$ & 3.290 .169 & $33,6 \%$ \\
\hline Estrato 6 & 1.536 .393 & $15,8 \%$ & 2.362 .419 & $22,0 \%$ & 1.980 .637 & $20,2 \%$ \\
\hline Estrato 7 & 225.284 & $2,3 \%$ & 970.762 & $9,0 \%$ & 124.250 & $1,3 \%$ \\
\hline Sin especificar & 292.208 & $0,0 \%$ & 1.615 .591 & $0,0 \%$ & 849.123 & $0,0 \%$ \\
\hline Total & 9.696 .982 & $100,0 \%$ & 10.731 .030 & $100,0 \%$ & 9.806 .317 & $100,0 \%$ \\
\hline
\end{tabular}

Fuente: censos nacionales de población de 1980, 1991 y 2001. 
La subestimación de los asalariados sin calificación que ello comporta solo modera levemente las tendencias observadas. ${ }^{10}$ Eso nos conduce al segundo problema. El alto porcentaje de casos sin especificar en 1991 y en 2001. En 1991 la fuerte caída del estrato 5 y su nueva, también importante, recuperación en 2001 hacen pensar que los casos sin especificar se encuentran sesgados, y que existe entre ellos un alto número de asalariados de calificación operativa. En 2001, como ya hemos visto antes, existe una fuerte subestimación de los trabajadores informales, lo que ha debido impactar particularmente en el estrato 7 , que reúne a los trabajadores por cuenta propia sin calificación.

Incluso considerando los sesgos, es posible identificar una tendencia a la caída del estrato 5 (asalariados con calificación operativa) y una tendencia al aumento del estrato 6 (asalariados sin calificación), así como una tendencia al aumento de los asalariados técnicos (estrato 4) y de los asalariados y trabajadores por cuenta propia profesionales (estrato 2). ${ }^{11}$ Es evidente que la tendencia de transformación de la estructura de estratos sociales está determinada por la tendencia de transformación de la composición de clase de los asalariados según calificación. Lo que en el análisis marxista de clase se manifiesta como una heterogeneización de la clase obrera según calificación — problema de la composición de clase que se liga inmediatamente con la cuestión de la relación de fuerzas entre capitalistas y trabajadores-, en el análisis de estratificación social se observa como un proceso de transformación de la diferenciación social de los individuos según probabilidades de vida.

Las consecuencias más relevantes de lo expuesto se observan en el cuadro 16, que presenta la evolución del esquema de tres clases a lo largo de los tres censos. Allí se observa una tendencia al crecimiento de la clase media entre 1980 y 2001 . La expansión de la clase media tiene como fundamento el crecimiento de los asalariados técnicos y profesionales, aun en un contexto de leve caída de los pequeños propietarios. En términos de Poulantzas (1985), es un crecimiento de las nuevas clases medias. Es por esa razón que proletarización y aumento de las clases medias pueden darse juntos. El término proletarización corresponde al análisis marxista de clase y designa el aumento del espacio social ocupado por las personificaciones de clase y del grado de socialización como índice de la composición de clase. La expansión de las clases medias refiere a la simultánea diferenciación social de los individuos que produce la subsunción del trabajo al capital, proceso de liberación de individuos y de su sujeción como clase. En el caso argentino, durante las últimas décadas ambos fenómenos han sido registrados de diversos modos.

Si dicha expansión está en la base de los procesos de movilización de clase media que se han desarrollado en las últimas décadas (Piva, 2012; 2014), depen-

10. Según el censo de 1991, dos tercios de los vendedores asalariados eran trabajadores sin calificación. Por el contrario, los asalariados clasificados como empleados en 1980 son clasificados en 1991 casi en su totalidad como trabajadores con calificación operativa. Si agrupáramos, siguiendo el criterio de 1980, a todos los vendedores asalariados de 1991 junto con los asalariados de calificación operativa, su proporción se elevaría desde el $24 \%$ al $26 \%$.

11. En el censo de 2001 no es posible identificar a los jefes y supervisores (estrato 4 bis). 
Cuadro 16. Evolución de estratificación social en Argentina entre 1980 y 2001. Esquema de tres clases.

\begin{tabular}{lrrrrrr}
\hline Clase alta & 195.498 & $2,0 \%$ & 295.135 & $2,8 \%$ & 306.614 & $3,1 \%$ \\
Clase media & 3.356 .747 & $34,6 \%$ & 4.109 .307 & $38,3 \%$ & 4.104 .647 & $41,9 \%$ \\
Clase popular & 6.144 .737 & $63,4 \%$ & 6.326 .588 & $59,0 \%$ & 5.395 .056 & $55,0 \%$ \\
Sin especificar & 292.208 & & 1.615 .591 & & 849.123 & \\
Total & 9.989 .190 & $100,0 \%$ & 12.346 .621 & $100,0 \%$ & 10.655 .440 & $100,0 \%$ \\
\hline
\end{tabular}

Fuente: censos nacionales de población de 1980, 1991 y 2001.

de del grado en que los esquemas propuestos reproducen un espacio de intercambios regulares probables entre individuos capaz de crear efectos de comunidad. Dalle señala la existencia de un espacio de fluidez en términos de movilidad que, más allá de ciertas diferencias en la clasificación, tiende a coincidir con el de las situaciones de clase agrupadas en nuestro modelo como clase media y que se extiende a parte del estrato de los asalariados de calificación operativa. También señala Dalle que las fronteras entre manuales calificados y no calificados no son cerradas, sino que están abiertas a la movilidad intergeneracional de tramo corto (Dalle, 2016). Lo que ello nos señalaría, con relación a nuestros resultados, es que si los intercambios regulares entre los individuos que habitan el espacio de la clase media dan lugar a la constitución de una identidad político-cultural, su naturaleza fundamentalmente identitaria tendría capacidad de expandirse hacia la clase popular. Volveremos en las conclusiones sobre la importancia de combinar el análisis marxista y el sociológico con el fin de comprender procesos de composición/descomposición política de clase.

Los enfoques que han señalado la expansión de las clases medias en América Latina en las últimas décadas (Paramio, 2010) han sido confrontados por quienes demuestran que en ese mismo período se han producido fenómenos de empobrecimiento y de aumento de la desigualdad (López-Calva et al., 2014). Frente al dilema planteado - aumento de las clases medias o empobrecimiento masivola perspectiva desarrollada tiene una respuesta muy clara: jsí!, ;por supuesto!

\section{Conclusiones}

Como señalábamos en la introducción, este artículo tuvo un doble propósito. En primer lugar, aproximarse a un análisis empírico de las tendencias de evolución de las relaciones estructurales de clase y de los procesos de estratificación social en Argentina desde 1947. En segundo lugar, contrastar empíricamente en un caso concreto las nociones marxista y sociológica de clase con el objetivo de obtener algunas conclusiones sobre su productividad, complementariedad y oposición.

Respecto del primer objetivo, el análisis de la clase como relación social objetiva nos mostró una ruptura en las tendencias de evolución entre los períodos 1947-1974 y 1974-2010. Entre 1947 y 1974 los datos evidencian un incremento absoluto de las personificaciones del trabajo, una disminución absoluta del número de patrones y una simultánea reducción del espacio social ocupado 
por personificaciones de clase, resultado de la expansión del trabajo por cuenta propia. Dicho fenómeno, dado su carácter, es expresión de un debilitamiento de la sobrepoblación relativa que, junto a una creciente homogeneidad de la composición de clase obrera en el marco de un proceso de aumento de su grado de socialización, tendió a potenciar las capacidades estructurales para la acción colectiva de los trabajadores. Los datos desde 1974, a su vez, evidencian dos subperíodos. El análisis según «categoría ocupacional» de los censos de población muestra que entre 1970 y 1991 tiende a caer la proporción de asalariados y a crecer la proporción de trabajadores por cuenta propia y patrones, así como a caer el espacio social ocupado por personificaciones de clase. Sin embargo, el análisis más preciso de la clase como relación social objetiva que permiten los censos de población desde 1980 muestra que entre 1980 y 1991 se estanca la proporción de asalariados y patrones, así como la del espacio social de relaciones de clase. Ello es resultado de la inclusión de los desocupados y de los trabajadores por cuenta propia no calificados entre la clase obrera. Lo que es consistente con el cambio de papel del cuentapropismo, cuyo crecimiento tiende a expresar el aumento de la sobrepoblación relativa. Entre 1991 y 2010 crece la proporción de asalariados hasta alcanzar los niveles de 1970, decrece el trabajo por cuenta propia y también decrece el porcentaje de patrones en un contexto de incremento del espacio social ocupado por personificaciones de clase. Sin embargo, todo el período, en contraposición al período 1947-1974, muestra una tendencia a la heterogeneización de la composición de clase obrera y a un aumento de la sobrepoblación relativa que debilitó las capacidades estructurales para la organización de la acción colectiva de los trabajadores.

Estos resultados son consistentes con la periodización propuesta del modo de acumulación. Durante el período ISI, el tipo de dualización de la estructura económica tendió a coincidir con la oposición ciudad/campo, lo que dio lugar a esa dinámica homogeneizadora del trabajo urbano, cuyas tendencias de desarrollo tenían su núcleo en la acumulación de capital en la industria. La tendencia a la heterogeneización del trabajo urbano desde 1976 es consistente con la existencia de un proceso de reestructuración en curso desde el golpe militar de ese año. Sin embargo, la evidencia de dos subperíodos en las tendencias de evolución de las relaciones objetivas de clase, 1974-1991 y 1991-2010, es consistente con la identificación de dos subperíodos de la acumulación de capital: 1976-1989 y 1989-2011. Por un lado, la tendencia a la estabilización del peso de los patrones y de los asalariados en la estructura de clases entre 1980 y 1991 es compatible con un período de reestructuración productiva bloqueada, estancamiento y/o caída del PBI y más en general de ausencia de desarrollo capitalista. Por otro lado, las tendencias desde 1991 a la proletarización, a la caída relativa del número de patrones (más aun en un contexto de aumento de su número absoluto) y a la profundización de la heterogeneización de la composición de clase de los trabajadores son indicadores consistentes con el despliegue de un proceso de reestructuración productiva, de crecimiento económico basado en la acumulación de capital productivo y de desarrollo capitalista dependiente. 
El análisis de la evolución del proceso de estatificación social entre 1980 y 2001 fue realizado a partir de un modelo exploratorio de siete estratos y tres clases construido a partir de tres dimensiones: la propiedad de los medios de producción, la autoridad en el proceso de trabajo y la calificación. Los datos evidencian una tendencia a la caída del estrato 5 (asalariados con calificación operativa) y una tendencia al aumento del estrato 6 (asalariados sin calificación), así como una tendencia al aumento de los asalariados técnicos (estrato 4) y de los asalariados y trabajadores por cuenta propia profesionales (estrato 2). Pero las consecuencias más relevantes de esta evolución se expresan en la evolución del esquema de tres clases a lo largo de los tres censos, una expansión de la clase media que tiene como fundamento el crecimiento de los asalariados técnicos y profesionales, aun en un contexto de leve caída de los pequeños propietarios. Esto es, un aumento de las nuevas clases medias que señala la existencia simultánea de un proceso de proletarización, ya observado en el análisis de la clase como relación objetiva, y de crecimiento de las clases medias de acuerdo a la distribución de los individuos según clases sociológicas.

Como señalamos antes, la estructura de clases desde una perspectiva marxista no es más que: 1) la distribución de los individuos como nudos/personificaciones de relaciones sociales de clase en un momento dado; 2) un índice del grado de composición (técnica) del obrero colectivo, como momento subjetivo de la relación de capital. Por ello el análisis de clase como relación objetiva se movió desde la distribución de individuos como personificaciones de relaciones de clase hacia atributos crecientemente colectivos que intentaron dar cuenta de la composición de clase de los asalariados, de su constitución objetiva como realidad colectiva y no como clasificación de individuos según atributos sociales.

Por el contrario, lo que subyace al análisis realizado en el último apartado es una operación analítica común a todos los enfoques de la estratificación social, aun los de inspiración marxista: 1) la individualización de los sujetos; 2) su clasificación según atributos sociales significativos. El resultado es entonces una explosión de las clases en un número a priori indeterminado de estratos. Esta operación, sin embargo, no es del todo arbitraria. La subsunción del trabajo al capital se manifiesta como un proceso simultáneo de «liberación» de individuos y de su sujeción como «clase». La operación sociológica reproduce ese proceso de diferenciación social que tiene como base la producción de individuos y la determinación desigual de sus probabilidades de vida por la contradicción capital/trabajo.

¿Cuál de los dos procedimientos — análisis de clase marxista, análisis de clase sociológico- debemos utilizar? Ambos. En la medida que aprehenden el proceso simultáneo de constitución de las relaciones como relaciones de clase y de diferenciación social de los individuos según probabilidades de vida, ambos procedimientos juntos (pero no mezclados) representan las condiciones estructurales de potenciales procesos de composición/descomposición política de clases. Dicho de un modo intencionalmente simplificado, son el reflejo teórico del antagonismo que organiza las relaciones sociales en el capitalismo. 


\section{Referencias bibliográficas}

BASuAldo, Eduardo (2006). Estudios de historia económica argentina. Desde mediados del siglo XX a la actualidad. Buenos Aires: Siglo XXI.

Bonnet, Alberto (2008). La hegemonía menemista. Buenos Aires: Prometeo.

Bourdieu, Pierre (1988). La distinción. Criterio y bases sociales del gusto. Madrid: Taurus.

- (1989). «El espacio social y la génesis de las clases». Estudios sobre las Culturas Contemporáneas, 3 (7), 27-55.

Braun, Oscar; Joy, Leonard (1981). «Un modelo de estancamiento económico, estudio de caso sobre la economía argentina». Desarrollo Económico, 80 (20). $<$ https://doi.org/10.2307/3466720>.

Cantamutto, Francisco; Costantino, Agostina (2016). «El modo de desarrollo en la Argentina reciente». Mundo Siglo XXI, 39 (21).

Carchedi, Guglielmo (1977). The economic identification of Social Classes. Londres: Routledge and Kegan Paul Ed.

Chan, Tak Wing; Goldthorpe, John (2007). "Class and Status: The Conceptual Distinction and its Empirical Relevance». American Sociological Review, 70 (72), $512-532$. $<$ https://doi.org/10.1177/000312240707200402>.

Dalle, Pablo (2016). Movilidad social desde las clases populares: un estudio sociológico en el Área Metropolitana de Buenos Aires: 1960-2013. Buenos Aires: IIGG-CLACSO.

DiAmAND, Marcelo (1972). «La estructura productiva desequilibrada argentina y el tipo de cambio». Desarrollo Económico, 45 (12). $<$ https://doi.org/10.2307/3465991>.

Donaire, Ricardo et al. (2018). «Superpoblación relativa en Argentina. Construcción de un instrumento para su relevamiento sistemático y estandarizado». Pimsa. Documentos y Comunicaciones, 5-94.

Franco, Rolando et al. (2011). "Crece y cambia la clase media en América Latina: una puesta al día». Revista de la CEPAL, 103, 7-26. <https://doi.org/10.18356/18a949a2-es>.

Germani, Gino (1955). Estructura social de la Argentina: análisis estadístico. Buenos Aires: Raigal.

Goldthorpe, John; Mcknigth, Abigail (2004). The economic basis of social class. Londres: LSE.

Gunn, Richard (2004). «Notas sobre clase». En: Holloway, John (comp.). Clase = Lucha, 17-32. Buenos Aires: Herramienta Editores.

Holloway, John (comp.) (2004). Clase = Lucha . Buenos Aires: Herramienta Editores.

IÑigo Carrera, Nicolás; Podestá, Jorge (1985). «Análisis de una relación de fuerzas sociales objetiva: caracterización de los grupos sociales fundamentales en la Argentina actual». Cuadernos de Cicso, 1-83.

IÑigo CARrera, Nicolás et al. (2012). «La superpoblación relativa en Argentina actual: un ejercicio de medición». Pimsa. Documentos y Comunicaciones, 104-161.

Jorrat, Raúl (2005). «Aspectos descriptivos de la movilidad intergeneracional de clase en Argentina: 2003-2004». Ponencia presentada al $7^{\circ}$ Congreso Nacional de Estudios del Trabajo. Buenos Aires: Aset.

Kessler, Gabriel; Espinoza, Vicente (2007). «Movilidad social y trayectorias ocupacionales en Buenos Aires. Continuidades, rupturas y paradojas». En: Franco, Rolando et al. (coord.). Estratificación y movilidad social en América Latina. Transformaciones estructurales de un cuarto de siglo. Santiago de Chile: CEPAL. 
LaClau, Ernesto; Mouffe, Chantal (2004). Hegemonía y estrategia socialista. Buenos Aires: Fondo de Cultura Económica.

Lockwood, David (1962). El trabajador de la clase media. Un estudio sobre la conciencia de clase. Madrid: Aguilar.

López-CAlva, Luis et al. (2014). "Clases medias y vulnerabilidad a la pobreza. Reflexiones desde América Latina». El Trimestre Económico, 2 (81), 281-307. <https://doi.org/10.20430/ete.v81i322.115>.

Negri, Antonio (2001). Marx más allá de Marx. Cuaderno de trabajo sobre los Grundrisse. Madrid: Akal.

Paramio, Ludolfo (2010). «Economía y política de las clases medias en América Latina». Revista Nueva Sociedad, 229, 62-75.

PARKIN, Frank (2001). "Strategies of social closure in class formation». En: PARKIN, Frank (ed.). The social analysis of class structuture. Londres: Routledge. <https://doi.org/10.4324/9781351067904-1>.

Parsons, Talcott (1976). El sistema social. Madrid: Revista de Occidente.

Pinto, Anibal (1970). "Naturaleza e implicaciones de la "heterogeneidad estructural" de la América Latina». El Trimestre Económico, 37 (145), 83-100.

Piva, Adrián (2012). Acumulación y hegemonía en la Argentina menemista. Buenos Aires: Biblos.

- (2014). «La movilización antikirchnerista de clase media. Entre la crisis de representación y la recomposición neopopulista del consenso». Revista Astrolabio. Nueva época, 12, 394-421.

- (2017a). "Clase y estratificación desde una perspectiva marxista». Revista Conflicto Social, 10 (17), 170-220.

- (2017b). «El modo de acumulación de capital en Argentina (1989-2015)». Revista Ensambles, 3 (6), 53-79.

Poulantzas, Nicos (1975). «Las clases sociales». Las clases sociales en América Latina: Problemas de conceptualización (Seminario de Mérida). México: Siglo XXI Editores.

- (1985). Las clases sociales en el capitalismo actual. México: Siglo XXI Editores.

Prebisch, Raúl (1949). El desarrollo económico de la América Latina y algunos de sus principales problemas. Santiago de Chile: CEPAL.

SAcco, Nicolás (2016). "Las clases sociales en la Argentina según los censos de población de 1991 y 2001». Revista Argentina de Estadistica Aplicada, 3, 1-17.

Salvia, Agustín; Quartulli, Diego (2011). «La movilidad y la estratificación socioocupacional en la Argentina». Lavboratorio, 12 (24), 145-174.

SAvage, Mike et al. (2005). "Capital, assets, and resources: some critical issues». The British Journal of Sociology, 56 (1), 31-47. Londres.

Schvarzer, Jorge (2000). Implantación de un modelo económico. La experiencia Argentina entre 1975 y el 2000. Buenos Aires: AZ Editora.

Torrado, Susana (1994). Estructura social de la Argentina: 1945-1983. Buenos Aires: Ediciones de la Flor.

Tronti, Mario (2001). Obreros y capital. Madrid: Akal.

Weber, Max (2002). Economía y sociedad. Esbozo de sociología comprensiva. México: Fondo de Cultura Económica.

Wright, Erik Olin (1983). Clase, crisis y estado. Madrid: Siglo XXI.

- (1994). Clases. Madrid: Siglo XXI.

- (1997). Class Counts. Cambridge: Cambridge University Press.

- (2015). Understanding class. Londres: Verso. 